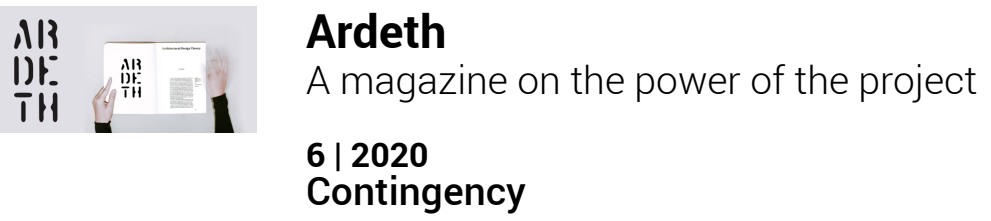

\title{
Production for Reduction
}

\section{Keigo Kobayashi}

\section{(2) OpenEdition \\ Journals}

Electronic version

URL: http://journals.openedition.org/ardeth/1218

ISSN: 2611-934X

Publisher

Rosenberg \& Sellier

Printed version

Date of publication: 1 September 2020

Number of pages: 221-232

ISSN: 2532-6457

\section{Electronic reference}

Keigo Kobayashi, «Production for Reduction », Ardeth [Online], 6 | 2020, Online since 01 November 2020, connection on 13 November 2020. URL : http://journals.openedition.org/ardeth/1218 


\section{Production for Reduction}

Keigo Kobayashi

Abstract

Today, the city of Tokyo is confronting several prominent social issues, such as extreme aging, a growing single population and the beginning of population shrinkage. There are around 810,000 empty houses in the city while many new apartments are still being built, replacing family owned factories with small rooms for singles.

As the new technology in urban factories trigger the shift from "how to make" to "what to make" in production, more focus shall be given to production steps such as "meet”, "talk", "inspire”, "think" and "share”. Coincidentally, these steps are what is often missing from the daily lives of those living alone in new apartments, isolated from the existing neighborhoods.

What if a factory aims at combining, there in the city, the production of living activities with the production of products? A theoretical project has challenged this question as part of a pursuit of new ideas for the time of reduction.
Affiliation

Waseda University, Department of Architecture

Contacts:

k [underscore]

kobayashi [at] waseda [dot] jp

Received:

19 August 2019

Accepted:

01 April 2020

DOI:

10.17454/ARDETH06.16

ARDETH\#06 


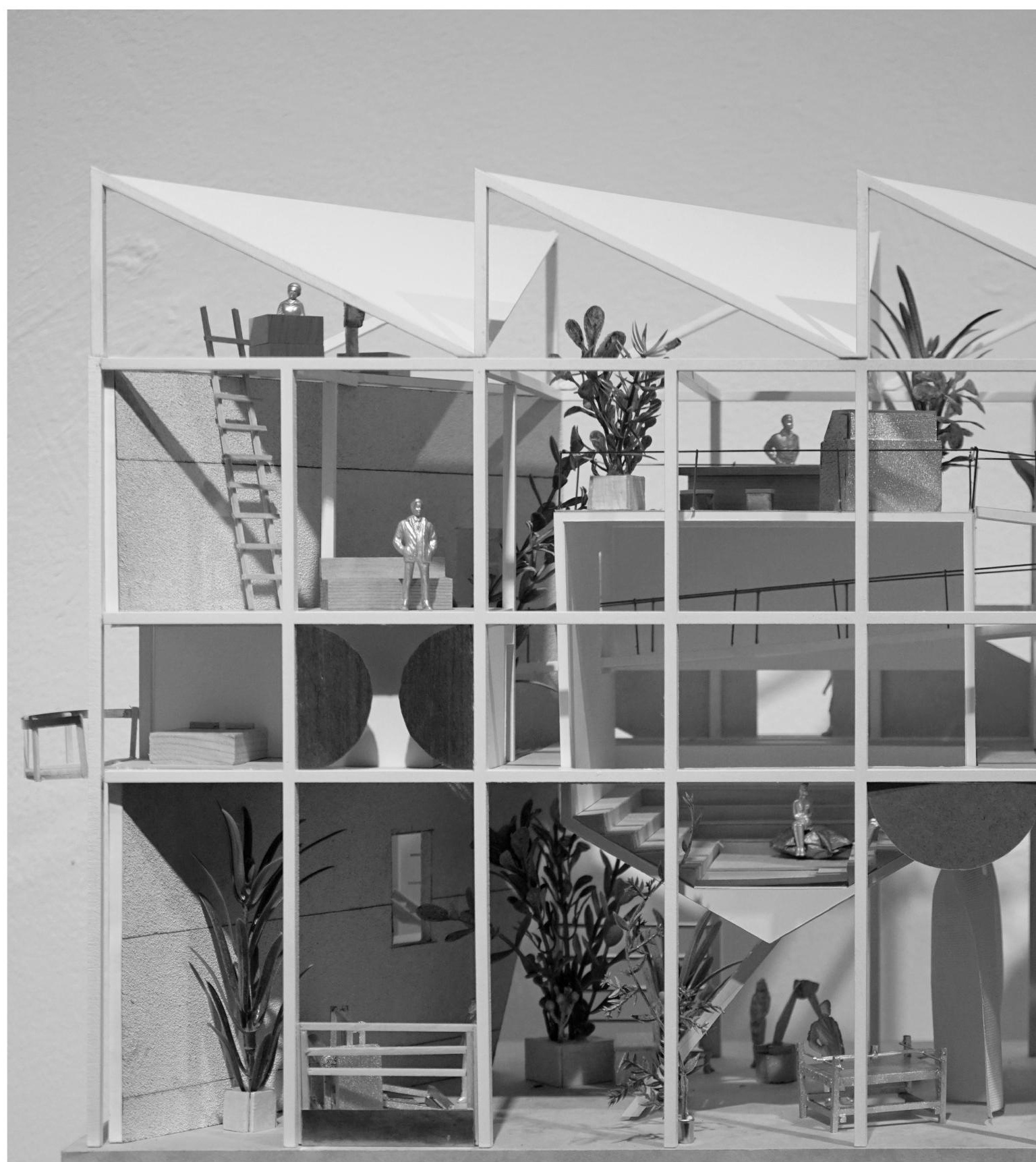




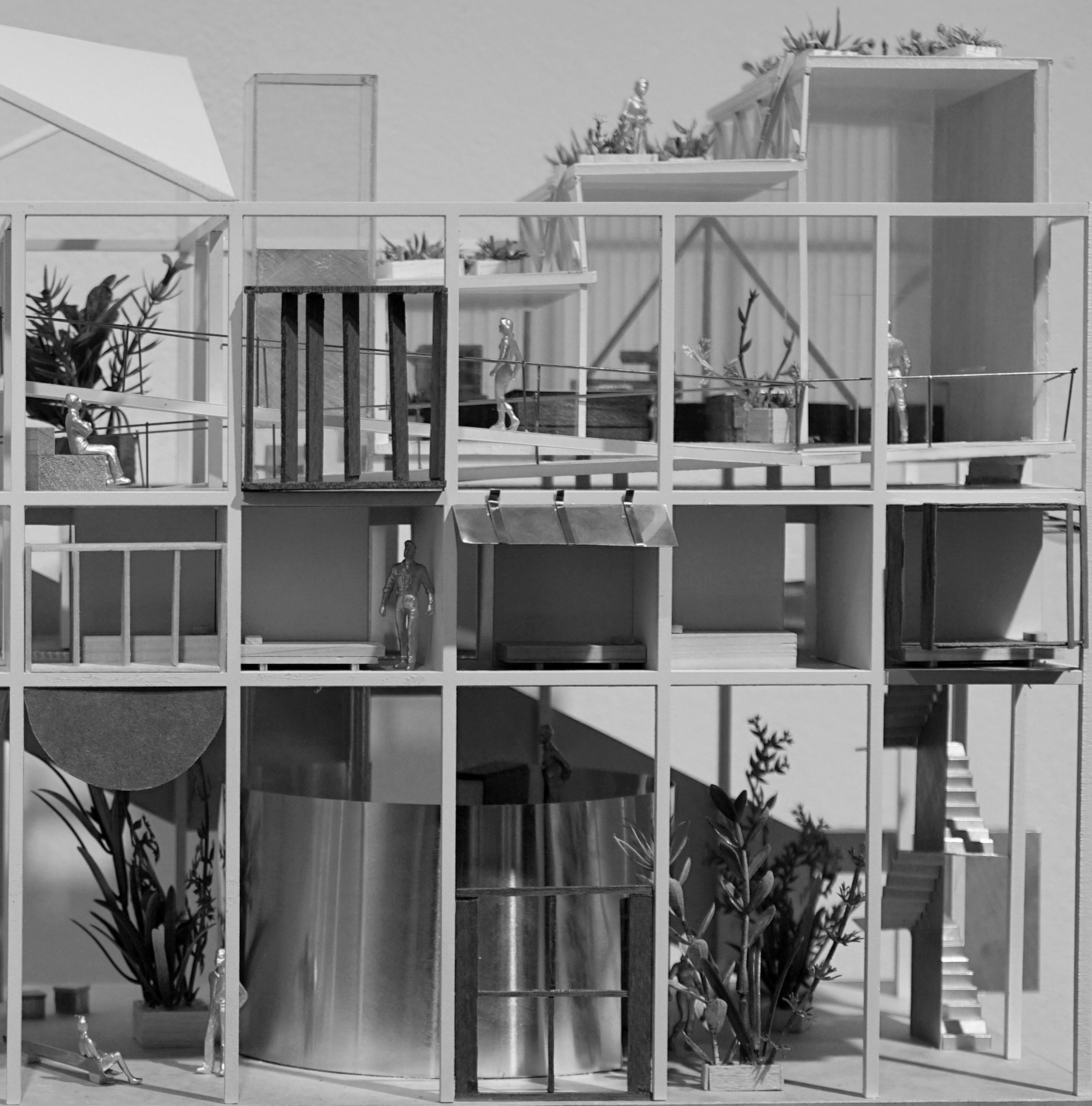




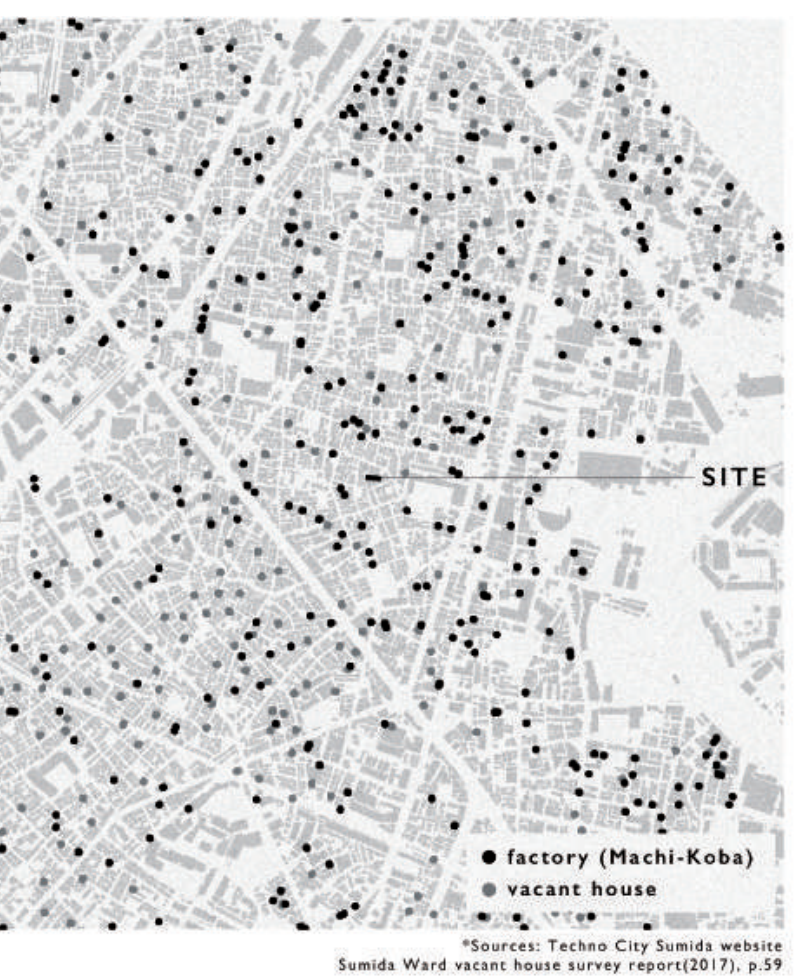

Factories and vacant houses around the site

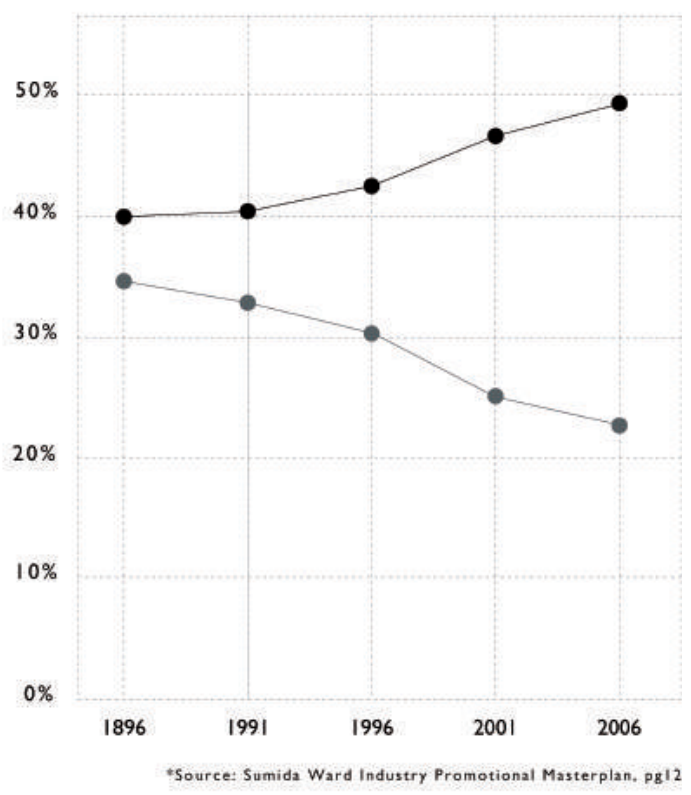

Change of the land use in Sumida
Fig. 1 - (Previous page) Exterior view.

Fig. 2 - Machi-Koba distribution and land use transition.
Shrinking population, extreme aging, low birth rate, but a growing singles population are some of the prominent social structures underpinning the 2020 Olympics preparation for Japan (Eberstadt, 2012). Unlike the 1964 Tokyo Olympics, when the economy was growing and industries were flourishing, today the city of Tokyo is confronting a very different set of issues and is in need of new ideas that can accommodate residents' desires at a time of reduction.

The issue of shrinking cities is certainly not limited to Japan, as Oswalt (2005) has extensively indicated, and there are many cities across Japan which better suit the shrinking definition than Tokyo. According to the Tokyo Metropolitan Government (2016), the population of Tokyo will only start declining after the year 2025, but the situation in current day Tokyo may suggest shrinkages in connections rather than its overall numbers. While there are around 810,000 empty houses in Tokyo (Minis- 


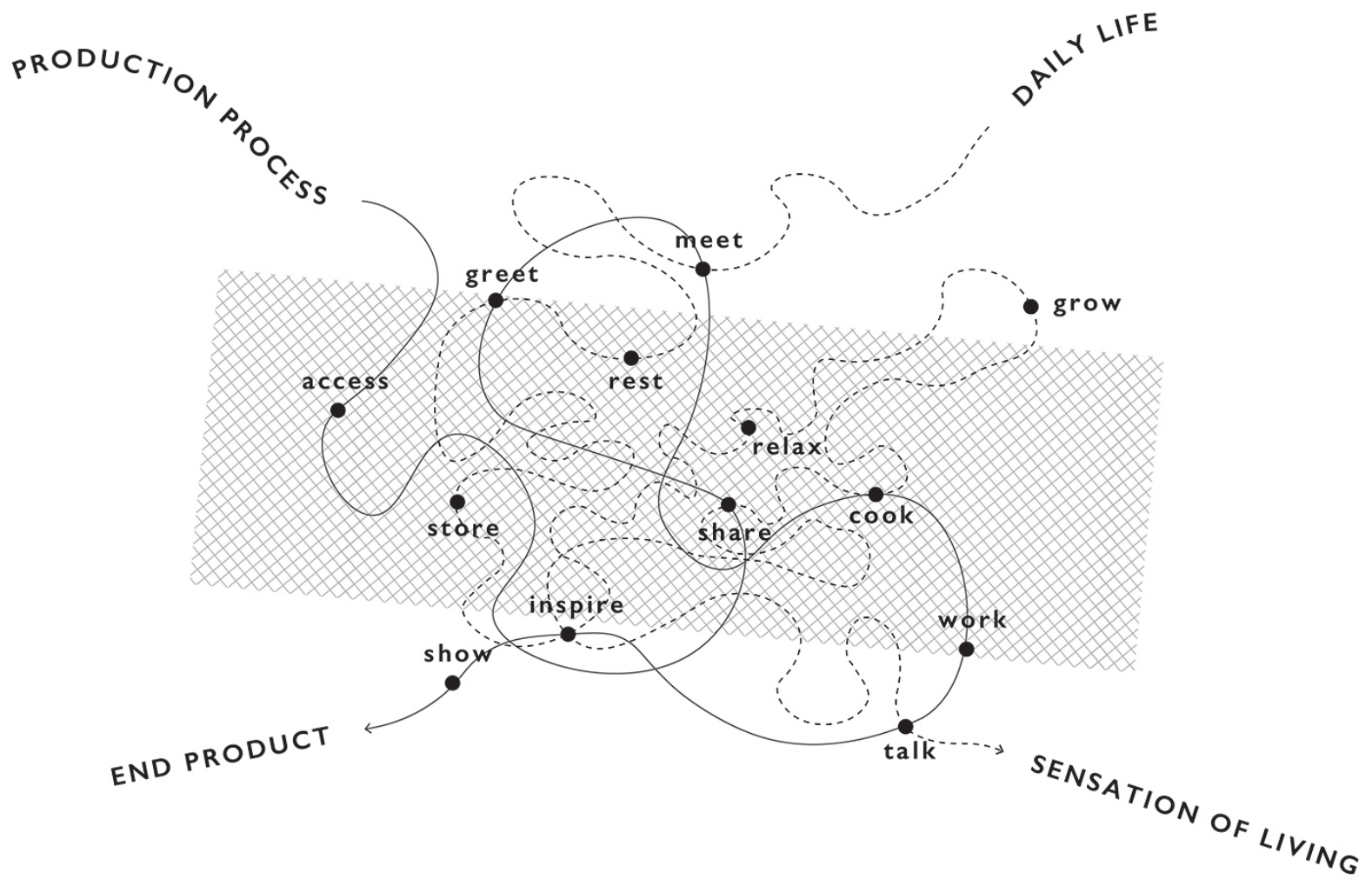

Factory $=$ Housing

try of Internal Affairs and Communications, 2018), mostly due to missing inheritors and building deterioration at various levels, ironically, new residential construction is still increasing in central Tokyo (Ministry of Land, Infrastructure, Transport and Tourism, 2018), replacing former factories, warehouses, and public bathhouses in residential neighborhoods. The typical inhabitants of these new apartments are singles moving in from outside the town, who account for 50\% of Tokyo's households today (Ministry of Land, Infrastructure, Transport and Tourism, 2013). They are often isolated from the existing social circles, rapidly weakening the communal ecologies that had previously stitched the neighborhoods together. A research conducted by Tokyo Gas Urban Life Laboratory (2016) reveals that $70 \%$ of singles living in apartments in the Tokyo metropolitan area have no interaction with the surrounding neighborhoods.
Fig. 3 - Sharing of the two production processes. 
The factory can be opened to neighbors, where they can meet and get to know the new residents. 
Collaboration with some of the local factories of specific skill sets, can benefit each other.

Production flow

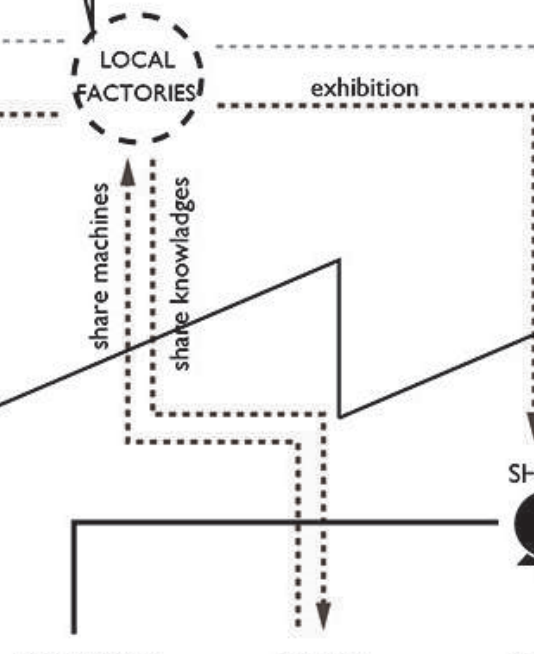

INTERSECT
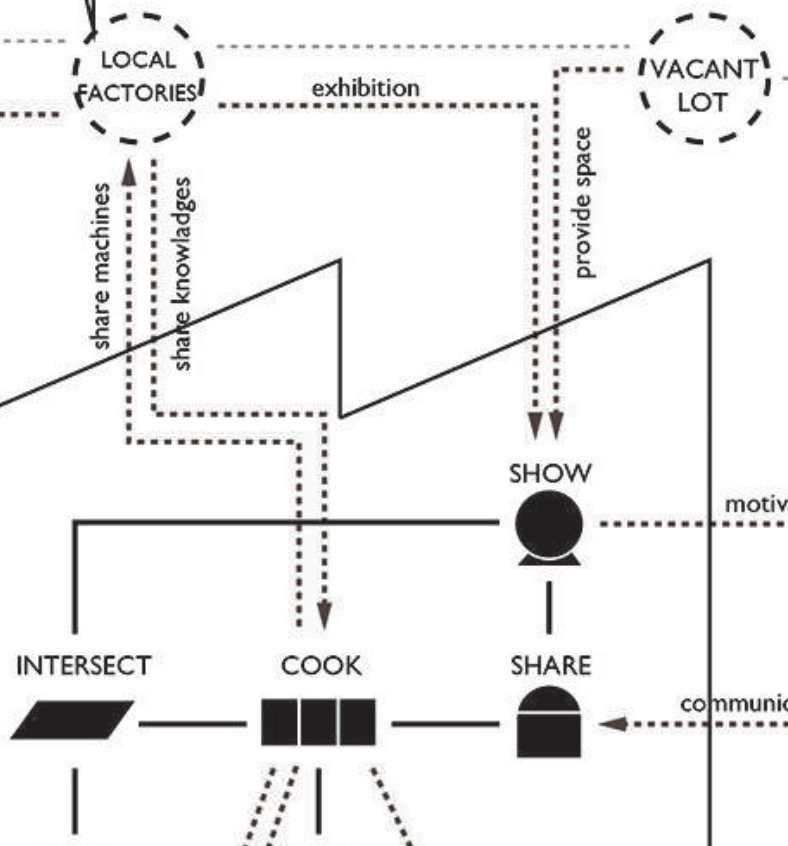

Fig. 4 - Overview of potential Machi-Koba network.

Nearby local schools can use the facility as off-site class room for workshops and lectures. Students can 


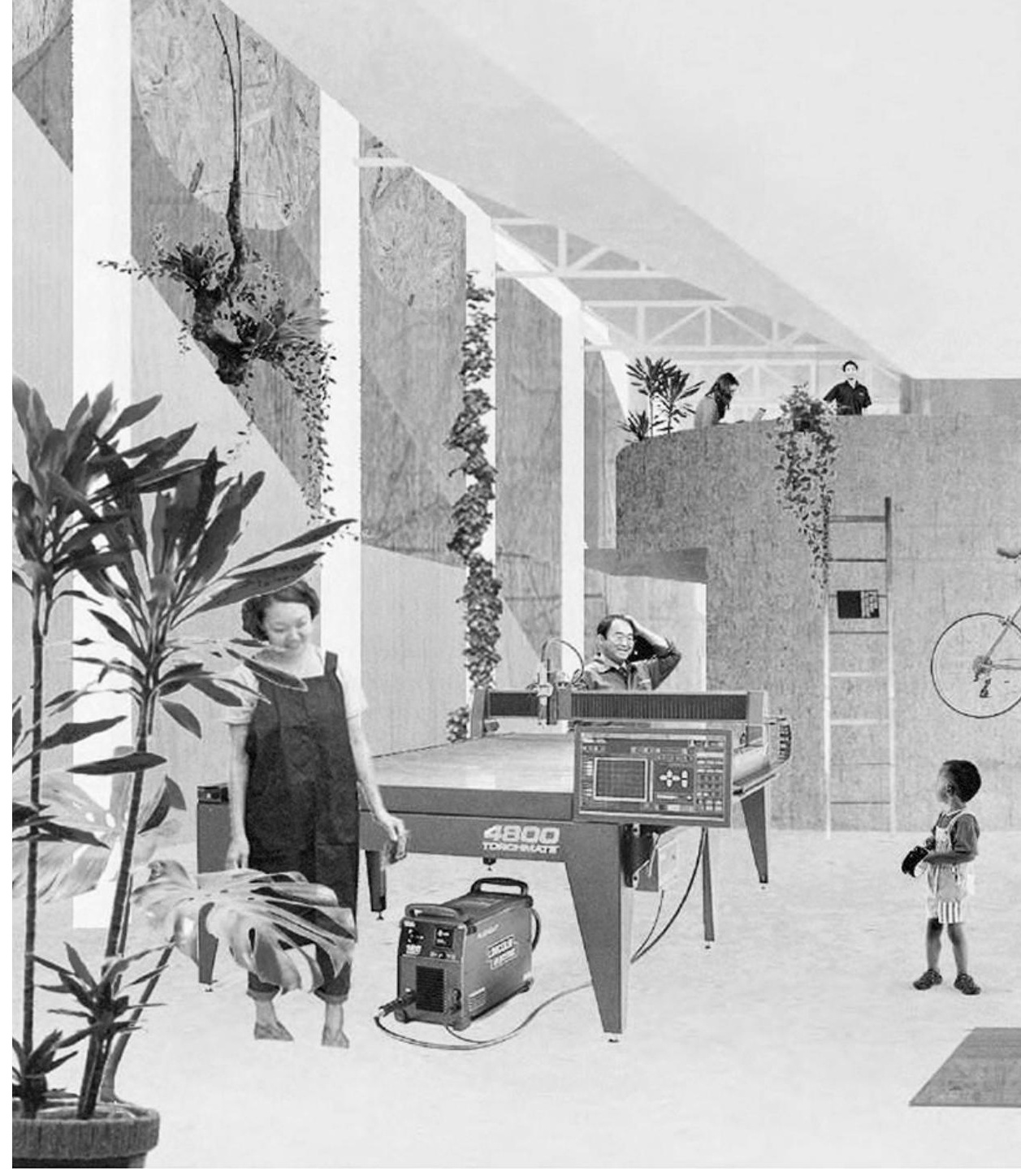

One hundred years ago the Tokyo government implemented the first modern master plan designating the Eastside of downtown Tokyo such as Sumida Ward into a major industrial zone, turning farmlands into factories for household commodities. Despite two complete tabula rasa erasures, one caused by the Great Kanto Earthquake of 1923 and the other by WWII bombing, the area reached its greatest population in 1963, at the dawn of the last Olympics (Sumida City Administrative Information, 2018). Since then, the large polluting factories were removed for environmental reasons. Only the family-owned small factories called Machi-Koba (town factory) remained in the area amongst dense wooden houses, providing work for the neighborhood and sustaining networks of business co-dependency. Today, one can still find outstanding craftsmanship in Machi-Koba, but they too are disappearing due to lack of work, an ageing workforce, and lack of younger generation to carry on the production, further accelerating the redevelopments of their plots (Sumida City Industrial Development Department, 2013). 
Meanwhile, as suggested by Rappaport (2016) in "Vertical Urban Factories" and by other efforts such as the "Maker City" in U.S. (Hirshberg et al., 2016) or "Cities of Making," research in Europe (Latitude Platform for Urban Design and Research, 2019), new technologies in production methods are widening the possibilities of re-introducing productive space within the urban context. Contrary to the mass production model of the last century, new technologies allow the shift in focus from "how to make" to "what to make," and thus the creativity becomes an essential part of the productive process (Anderson, 2010). Such steps as "meet”, "talk", "inspire”, "think" and "share" are considered to be necessary actions within the creative thinking process (Brown, 2008), and therefore of the productive process. When revisiting Tokyo and its given situation, coincidentally, these steps are what is often missing from the daily lives of those living alone within apartment buildings, isolated from the existing neighborhoods. 


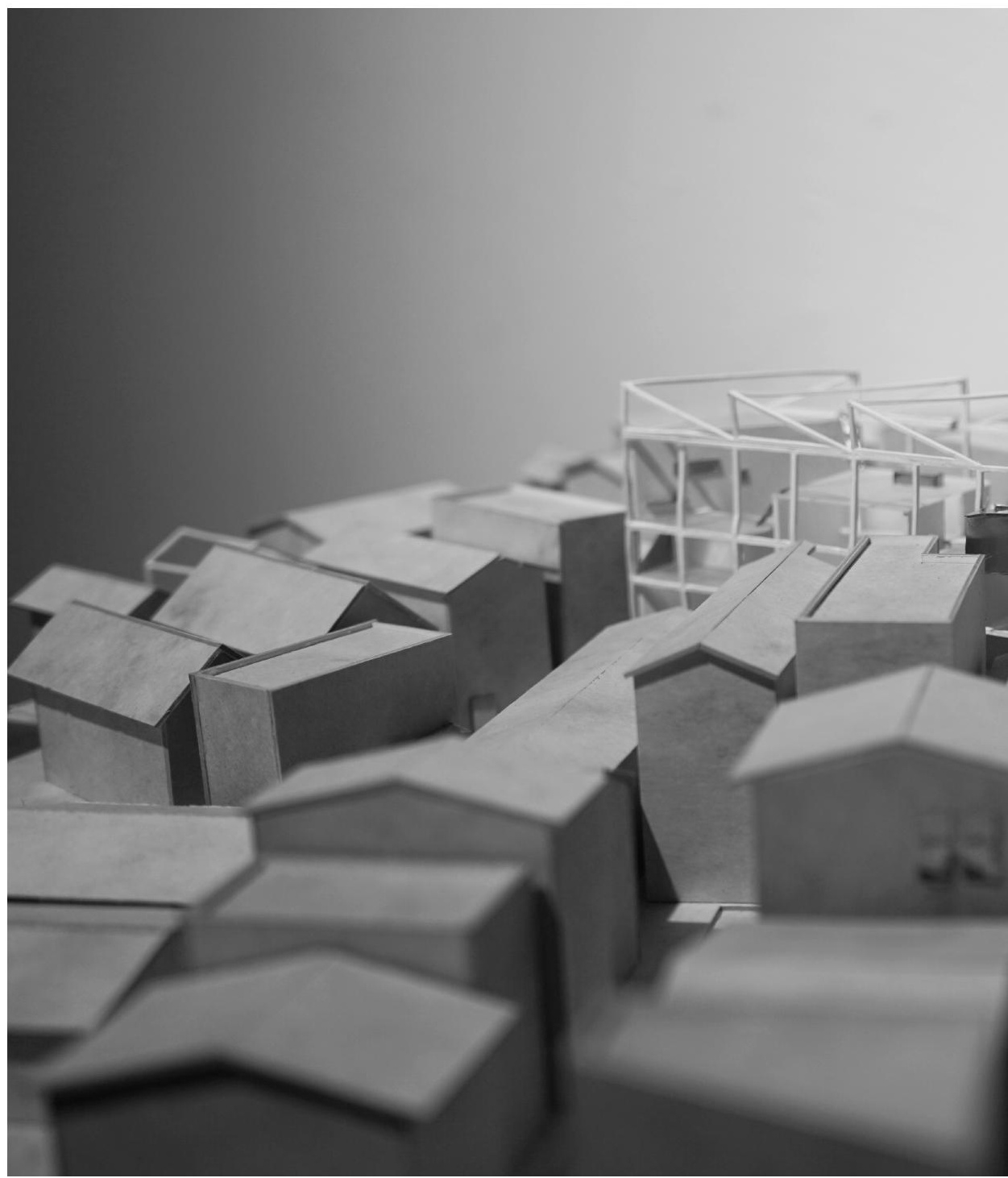

Machi-Koba used to be where local knowledge, skills, and human interactions were fostered. Some studies even show how these small factories and its networks play important roles in encouraging the development of local communities (Kakuda et al., 2009). Also, the typical typology of Machi-Koba is a hybrid of the productive space and the living space, often belonging to a family. What if this hybrid typology can be extended to the newcomers of the neighborhood? The combination of a local Machi-Koba factory and the apartment building for singles. Where those productive steps can take place through shared facilities such as a work station/ living room, meeting space/dining space, library/storage, and production studio/lobby. 




Perhaps this factory can produce customized elements of architecture, such as decorated doors, original window frames, staircases, balconies, etc. Elements which can be implemented into the empty building stocks in the neighborhood, physically upgrading the vacant houses into rent ready conditions. The single residents living in this factory will have more chance of being introduced by the factory workers to local building owners, and could eventually move into these renovated houses, slowly integrated into the community. Here the main act of production is not the making of the physical products but rather the making of relationships, eventually turning them into Koba (factory) for making the future Machi (neighborhood) resilient within the times of reduction. 


\section{References}

Anderson, C. (2010), In the next Industrial Revolution, atoms are the new bits, "Wired" [Online]. Available at: https://www.wired.com/2010/01/ff_newrevolution/ [Accessed: 21 April 2020].

Brown, T. (2008), Design thinking, "Harvard Business Review”, vol. 86, n. 6, pp. 84-92. Eberstadt, N. (2012), Japan shrinks, “The Wilson Quarterly”, vol. 36, n. 2, pp. 30-37. Hirshberg, P., Dougherty, D., Kadanoff, M. (2016), Maker City, San Francisco, Maker Media.

Kakuda, Y., Kim, S., Yokoyama, S., Tokuono, T. (2009), The Study on the Characteristics of Workplace, Residence and the Local Community in the Area of the Small Factories, Tokyo, Architectural Institute of Japan.

Latitude Platform for Urban Design and Research (2019), Cities of Making / Motivation [Online]. Available at: https://citiesofmaking.com/project/about-com/.

Ministry of Internal Affairs and Communications (2018), Statistical Survey of Residential Land 2018 [Online]. Available at: https://www.stat.go.jp/data/jyutaku/2018/ tyousake.html.

Ministry of Land, Infrastructure, Transport and Tourism (2013), Annual Report 2013 [Online]. Available at: https://http://www.mlit.go.jp/hakusyo/mlit/h24/hakusho/h25/.

Ministry of Land, Infrastructure, Transport and Tourism (2018), Statistical Trends in Housing Construction [Online]. Available at: https://www.mlit.go.jp/statistics/ details/t-jutaku-2_tk_000002.html.

Oswalt, P. (2005), Shrinking Cities Volume 1: International Research, Ostfildernm Hatje Cants.

Rappaport, N. (2016), Vertical Urban Factory, New York, Actar.

Sumida City Administrative Information (2018), History of Sumida Ward [Online]. Available at: https://www.city.sumida.lg.jp/kuseijoho/kunosyoukai/history.html.

Sumida City Industrial Development Department (2013), Sumida Ward Industrial Development Masterplan [Online]. Available at: https://www.city.sumida.lg.jp/kuseijoho/sumida_kihon/ku_kakusyukeikaku/sangyou_masterplan.files/stayfab.pdf. Tokyo Gas Urban Life Laboratory (2016), Urban Life Report 2016-No.03 [Online]. Available at: https://www.toshiken.com/report/community08.html.

Tokyo Metropolitan Government Office of the Governor for Policy Planning (2016), Action Plan Toward 2020 Chapter 4, [Online]. Available at: https://www.seisakukikaku.metro.tokyo.lg.jp/basic-plan/actionplan-for-2020/plan.html. 